Rev. Bras. Saúde Prod. Anim., Salvador, v.16, n.2, p.440-448 abr./jun.., 2015 http://www.rbspa.ufba.br

\title{
Utilização de diferentes dietas na primeira alimentação de larvas de tambaqui
}

\author{
Use of different diets in first feeding of tambaqui larvae
}

PEDREIRA, Marcelo Mattos ${ }^{1 *}$; SCHORER, Marianne ${ }^{1}$; FERREIRA, André Lima ${ }^{1}$

${ }^{1}$ Universidade Federal do Vale do Jequitinhonha, Laboratório de Aquicultura e Ecologia Aquática,
Diamantina, Minas Gerais, Brasil.
${ }^{*}$ Endereço para correspondência: marcelomattospedreira@gmail.com

\section{RESUMO}

O tambaqui Colossoma macropomum (Cuvier, 1818) (Characiformes: Characidae) nativo da Bacia Amazônica. É uma espécie reofílica que em cativeiro se reproduz somente através da indução hormonal. Sendo a larvicultura de espécies nativas uma das fases que exige maior atenção, o início da alimentação exógena exerce grande importância para a produção e sobrevivência de alevinos. Ao longo do desenvolvimento, as larvas de tambaqui passam por modificações morfo-fisiológicas e no hábito alimentar. O objetivo deste trabalho foi avaliar a utilização de diferentes dietas na primeira alimentação de larvas de tambaqui. As larvas de tambaqui foram cultivadas durante 20 dias, sob os seguintes tratamentos alimentares: plâncton; plâncton + ração; plâncton selecionado; plâncton selecionado + ração; e ração. A alimentação foi oferecida duas vezes ao dia, " $a d$ libitum". As variáveis físico-químicas mantiveram-se em limites aceitos para a espécie. Os tratamentos que utilizaram o emprego de alimentos vivos resultaram em melhor desempenho produtivo das larvas de tambaqui. A adição da ração associada ao alimento vivo na alimentação das larvas de tambaqui também melhorou o desempenho, embora esta não seja indicada como única fonte alimentar, nos primeiros dias de vida. Portanto, o emprego de alimento vivo acrescido de ração, a partir do terceiro dia de alimentação exógena, proporciona melhor desempenho produtivo e sobrevivência de larvas de tambaqui.

Palavras-chave: larvicultura, primeira alimentação, zooplâncton

\section{SUMMARY}

The tambaqui Colossoma macropomum (Cuvier, 1818) (Characiformes: Characidae) ia a native fish of the Amazon Basin. It is a rheophilic species, and in captivity the reproduction occurs only through hormonal induction. Larvae of native species require more attention in the first stages, so the first feeding has great importance for the fry production and survival. Throughout the development, the larvae of tambaqui undergo morphological and physiological changes and eating habits. The objective of this study was to evaluate the use of different diets on the first feeding tambaqui larvae. Tambaqui larvae were grown during 20 days under the following dietary treatments: plankton; plankton + ration; selected plankton; selected plankton + ration; and ration. The feed was given twice daily, "ad libitum". The physicchemical variables of water remained in limits accepted for the species. Treatments where it was used live food resulted in better growth performance of tambaqui larvae. The addition of ration associated with the live food to feed the tambaqui larvae also improved performance, although ration is not recommended as the sole food source, in the first days of life. Therefore, the use of live food plus ration, from the third day of exogenous feeding, improves a better growth performance and survival of tambaqui larvae.

Keywords: first feeding, fry production, zooplancton 
Rev. Bras. Saúde Prod. Anim., Salvador, v.16, n.2, p.440-448 abr./jun.., 2015 http://www.rbspa.ufba.br

\section{INTRODUÇÃO}

O tambaqui Colossoma macropomum (Cuvier, 1818) é um Characiformes da família Characidae, que alcança cerca de $1 \mathrm{~m}$ e $30 \mathrm{~kg}$, que até a década de 1980 era a espécie mais abundante na pesca na bacia amazônica. com destacado consumo, atingindo altos valores no mercado de Manaus (SANTOS \& SANTOS, 2005). Atualmente esta espécie vem sendo produzida devido as características favoráveis ao cultivo como a sua capacidade de reprodução em cativeiro (MENEZES et al., 2008; MUNIZ et al., 2008) e de assimilação e crescimento por se alimentar com rações com proteína a base de vegetal (LOPES et al., 2010; PEREIRA et al., 2013; PEREIRA JUNIOR et al., 2013), o que torna os custos com alimentação mais baixos.

Existe uma constante preocupação em se aprimorar a tecnologia de produção de larvas e alevinos de peixes nativos brasileiros. Contudo, freqüentes insucessos na criação de larvas de espécies nativas, têm sido observados nas fases iniciais, contribuindo com a baixa sobrevivência (BARCELLOS et al., 2004).

Nesta fase as larvas de peixes apresentam seu sistema digestório imaturo (PORTELLA \& DABROWSKI 2008) e não assimilam adequadamente as rações nos primeiros dias de vida (PEDREIRA et al., 2008; DIEMER et al., 2012), sendo portanto, o emprego de alimentos vivos uma prática comum na larvicultura de peixes (DIEMER et al., 2012).

Larvas de peixes tropicais dulcícolas, nos primeiros dias de alimentação exógena, capturam organismos menores, devido a sua pequena abertura de boca (MARQUES et al., 2007; DIEMER et al., 2012) e no decorrer do seu desenvolvimento apresentam eficiência de captura e selecionam suas presas (GRAEB et al., 2004; MARQUES et al., 2007; BRANDÃOGONÇALVES \& SEBASTIEN, 2013). Essa maior competência é devido a rápidas alterações de características funcionais, anatômicas, fisiológicas e comportamentais conduzindo a uma melhor eficiência alimentar (YÚFERA \& DARIAS 2005; PORTELLA \& DABROWSKI 2008).

Pelo fato de ao longo do desenvolvimento das larvas ocorrerem modificações morfo-fisiológicas e em seu hábito alimentar, este trabalho visa avaliar a utilização de alimento vivo, e sua associação com a ração na primeira alimentação do tambaqui.

\section{MATERIAL E MÉTODOS}

As larvas de tambaqui foram obtidas de desova induzida, e fornecidas pelas Centrais Elétricas de Minas Gerais (CEMIG). As larvas de três dias de idade apresentaram comprimento total médio de $6,63 \mathrm{~mm}$ e peso médio de 0,82 mg. O comprimento e peso inicial das larvas foram mensurados através do uso de uma ocular micrométrica, em um microscópio estereoscópico (Carl Zeiss Jena Dv4) e balança analítica $0,1 \quad$ (Scientch AS 210, China), respectivamente. Estas foram mantidas em 15 aquários com capacidade de 10L de água, numa densidade de 10 larvas $\mathrm{L}^{-1}$ (100 indivíduos tanque $\left.{ }^{-1}\right)$, com aeração constante e condições ambientais de fotoperíodo, luminosidade (1272 \pm 427 lux) e temperatura do ar (entre 24,5 a $33,0^{\circ} \mathrm{C}$ ), sendo cultivadas em laboratório durante 20 dias.

As larvas de tambaqui foram submetidas a cinco tratamentos alimentares, com três repetições cada, 
distribuídas aleatoriamente. Os tratamentos foram distribuídos da seguinte maneira: P (100\% plâncton, que foi selecionado com peneira de $1000 \mu \mathrm{m}) ;$ PR $(50 \%$ plâncton $+50 \%$ ração - plâncton foi selecionado com peneira de $1000 \mu \mathrm{m}$ e ração foi dada as larvas a partir do $3^{\circ}$ de vida das larvas); PS $(100 \%$ plâncton selecionado com peneira de $350 \mu \mathrm{m})$; PSR ( $50 \%$ plâncton selecionado $+50 \%$ ração - plâncton foi selecionado com peneira de $350 \mu \mathrm{m}$ e ração foi dada as larvas a partir do $3^{\circ} \mathrm{de}$ vida das larvas); $\mathrm{R}$ (100\% ração a partir do $3^{\circ}$ dia de vida das larvas).

$\mathrm{O}$ alimento foi oferecido duas vezes ao dia, às 8 e 14h, "ad libitum". Os tratamentos a base de alimentos vivos, ou seja, plâncton (Protozooa, Rotifera, Copepoda, náuplios de Copepoda, Cladocera, Ostracoda, Insecta, ovos de invertebrados e não identificados) foram coletados em tanques adubados, concentrado e posteriormente fracionado em peneiras de $1000 \mu \mathrm{m}$ e $350 \mu \mathrm{m}$. O tanque fornecedor de alimento vivo foi previamente adubado e posteriormente, os zooplânctons foram peneirados em uma rede conforme tratamento, e concentrado em béquer de 4,0L e triado em peneira de malha com $1.000 \mu \mathrm{m}$ de abertura. Metade desse volume (2,0L) foi transferida para outro frasco e triada em peneira de malha com $350 \mu \mathrm{m}$ de abertura. Em seguida, o zooplâncton foi homogeneizado e distribuído entre os aquários $(200 \mathrm{~mL}$ para cada aquário). Foi ofertado 450 presas por larva. As larvas alimentadas com ração receberam a proporção de $5 \%$ da biomassa total do aquário.

Diariamente, às $8 \mathrm{~h}$ foi medida a temperatura e o oxigênio dissolvido da água por meio de um oxímetro YSI 55 (YSI Inc, USA), o pH, com o pHmetro digital Corning PS 15 e a condutividade elétrica, com o condutivímetro digital Corning PS 17 (Sigma-Aldrich Co,
USA). A cada três dias, após a coleta dos dados limnológicos, os tanques foram sifonados para limpeza, sendo renovado $30 \%$ do volume de água.

Os valores de sobrevivência (\%), peso médio (mg), biomassa (g) e comprimento total $(\mathrm{mm})$ foram tomados ao término do experimento. Para obtenção de dados morfométricos, foram coletadas larvas aleatoriamente nos aquários, e estas foram sensibilizadas em gelo e fixadas em Bouin por $12 \mathrm{~h}$ e em seguida preservadas em álcool 70\%. Para cada repetição, o total de larvas foi pesado em balança Scientch (AS 210, China), precisão 0,1 $\mathrm{mg}$, considerando-se este valor a biomassa que, dividida pelo número de indivíduos, resultou no peso médio da larva. O comprimento total das larvas foi determinado por meio de uma ocular micrométrica, em um microscópio estereoscópico (Carl Zeiss Jena Dv4), medindo-se 50 larvas dos tratamentos plâncton selecionado, plâncton selecionado + ração e plâncton + ração e todas as larvas dos tratamentos plâncton e ração. Ao final do experimento foi contabilizado o total de larvas sobreviventes.

Os resultados das análises tiveram inicialmente suas médias e desvios padrão determinados, para posteriormente serem submetidos aos testes de Lilliefors e Levene, a fim de serem verificadas a normalidade e homocedasticidade. Todos os dados apresentaram normalidade $\mathrm{e}$ homogeneidade e posteriormente aplicouse ANOVA e teste de Tukey $(\mathrm{p}<0,05)$. As análises foram realizadas no programa SigmaStat 2.0.

\section{RESULTADOS E DISCUSSÃO}

Os parâmetros físicos e químicos da água dos tratamentos não apresentaram diferenças estatísticas $(\mathrm{P}>0,05)$ (Tabela 
Rev. Bras. Saúde Prod. Anim., Salvador, v.16, n.2, p.440-448 abr./jun.., 2015 http://www.rbspa.ufba.br ISSN 15199940

1) durante o período experimental e apresentaram valores dentro das condições esperadas para espécies tropicais (ARANA 2004; SILVA \& CARNEIRO, 2007).

As larvas de tambaqui alimentadas com PR apresentaram melhor $(\mathrm{P}<0,05)$ ganho de peso e comprimento, e biomassa, em relação aos demais tratamentos (Tabela 2). As larvas alimentadas com PSR apresentaram maior $(\mathrm{P}>0,05)$ sobrevivência.
As larvas alimentadas com $R$ apresentaram menor $(\mathrm{P}>0,05)$ sobrevivência que as larvas alimentadas com PSR, menor $(\mathrm{P}>0,05)$ peso do que as do tratamento $P R$ e $P$, menor $(P>0,05)$ biomassa do que as dos tratamentos $\mathrm{PR}$, PS e PSR e menor $(\mathrm{P}>0,05)$ comprimento total que as larvas alimentadas com $\mathrm{P}$ e PR $(\mathrm{P}<0,05)$, apresentado portanto baixo desempenho produtivo.

Tabela 1. Valores médios e desvios padrões dos parâmetros físico-químicos no cultivo de larvas de Colossoma macropomum após 20 dias em distintos tratamentos alimentares: plâncton $(\mathrm{P})$, plâncton + ração (PR), plâncton selecionado (PS), plâncton selecionado + ração (PSR) e ração (R)

\begin{tabular}{lcccc}
\hline Tipo de alimento & $\begin{array}{c}\text { Temperatura } \\
\left({ }^{\circ} \mathrm{C}\right)\end{array}$ & $\begin{array}{c}\text { Oxigênio dissolvido } \\
\left(\mathrm{mg} \mathrm{L}^{-1}\right)\end{array}$ & $\mathrm{pH}$ & $\begin{array}{c}\text { Condutividade elétrica } \\
\left(\mu \mathrm{S} \mathrm{cm}^{-1}\right)\end{array}$ \\
\hline P & $27,1 \pm 2,6$ & $7,3 \pm 0,5$ & $7,5 \pm 04$ & $44,3 \pm 12,9$ \\
PR & $27,0 \pm 2,5$ & $7,2 \pm 0,6$ & $7,2 \pm 0,8$ & $61,7 \pm 29,0$ \\
PS & $27,1 \pm 2,5$ & $7,3 \pm 0,4$ & $7,6 \pm 0,5$ & $38,6 \pm 7,8$ \\
PSR & $27,3 \pm 2,7$ & $7,3 \pm 0,5$ & $7,4 \pm 0,6$ & $50,6 \pm 18,4$ \\
R & $27,1 \pm 2,8$ & $7,4 \pm 0,6$ & $7,6 \pm 1,1$ & $63,6 \pm 30,8$ \\
\hline
\end{tabular}

Não apresentaram diferenças $(\mathrm{P}>0,05)$.

Tabela 2. Valores médios e desvios padrões do desempenho produtivo de larvas de tambaqui Colosoma macropomum após 20 dias de cultivo em distintos tratamentos alimentares: plâncton $(\mathrm{P})$, plâncton + ração $(\mathrm{PR})$, plâncton selecionado (PS), plâncton selecionado + ração (PSR) e ração (R)

\begin{tabular}{lcccc}
\hline Tipo de alimento & Sobrevivência (\%) & Peso $(\mathrm{mg})$ & Biomassa $(\mathrm{g})$ & Comprimento total $(\mathrm{mm})$ \\
\hline P & $48,4 \pm 25,2^{\mathrm{ab}}$ & $9,4 \pm 18,9^{\mathrm{b}}$ & $0,7 \pm 0,9^{\mathrm{ab}}$ & $7,4 \pm 14,4^{\mathrm{ab}}$ \\
PR & $49,4 \pm 27,0^{\mathrm{ab}}$ & $17,7 \pm 3,3^{\mathrm{a}}$ & $1,4 \pm 0,3^{\mathrm{a}}$ & $9,7 \pm 25,2^{\mathrm{a}}$ \\
PS & $47,2 \pm 40,3^{\mathrm{ab}}$ & $10,9 \pm 2,0^{\mathrm{bc}}$ & $0,6 \pm 0,3^{\mathrm{a}}$ & $7,1 \pm 25,2^{\mathrm{bc}}$ \\
PSR & $62,6 \pm 29,4^{\mathrm{a}}$ & $11,3 \pm 3,0^{\mathrm{bc}}$ & $0,7 \pm 0,3^{\mathrm{a}}$ & $7,2 \pm 25,2^{\mathrm{bc}}$ \\
R & $4,8 \pm 6,0^{\mathrm{b}}$ & $1,8 \pm 1,4^{\mathrm{c}}$ & $0,01 \pm 0,0^{\mathrm{b}}$ & $6,9 \pm 25,2^{\mathrm{c}}$ \\
\hline
\end{tabular}

Médias seguidas de letras minúsculas distintas indicam diferença entre os valores na coluna, segundo teste de Tukey $(\mathrm{p}<0,05)$.

As larvas de tambaqui alimentadas exclusivamente com ração apresentaram baixos valores de sobrevivência e peso médio, demonstrando que o alimento vivo é um fator primordial nos primeiros dias de vida, como descrito na literatura (LUZ \& ZANIBONI- FILHO, 2001; MANDAL et al., 2009; DAS et al., 2012). Resultados semelhantes foram observados com larvas do surubim-do-Iguaçú, Steindachneridion melanodermatum, onde o tratamento 
alimentar a base de ração proporcionou menores sobrevivências e ganho de peso (FEIDEN et al., 2006). Também para larvas de mandi-amarelo Pimelodus maculatus (WEINGARTNER \& ZANIBONI-FILHO, 2004) e de mandipintado Pimelodus britskii (DIEMER et al., 2010) a sobrevivência foi inferior para as larvas alimentadas somente com ração. Todos os parâmetros do desempenho produtivo dos tratamentos plâncton, plâncton selecionado, plâncton selecionado + ração, não diferiram entre si $(\mathrm{P}>0,05)$.

A capacidade das larvas de algumas espécies de peixes em digerir ou não dieta seca, é explicada pelas características morfológicas do trato digestivo e pelas enzimas secretadas ao longo do desenvolvimento (MARQUES et al., 2007; PORTELLA \& DABROWSKI, 2008). As larvas de peixes somente aceitam o alimento exógeno quando estão preparadas fisiologicamente para digerí-lo, e isso ocorre quando existe a atividade de protease ácida, indicando a funcionalidade do estômago (VEJAORELLANA et al., 2006). Caso contrário, larvas que não se alimentam exaurem suas reservas e morrem por inanição ou ficam suscetíveis à predação (BARAS \& JOBLING, 2002), o que justifica a baixa sobrevivência e o desenvolvimento inferior em peso e comprimento das larvas de tambaqui alimentadas exclusivamente com ração. A captura de presas vivas ativam as enzimas digestivas da larva, iniciando o processo de autólise (SERRANO JUNIOR, 2012), talvez pelo fato do alimento vivo obter a presença de enzimas proteolíticas, que auxiliam na digestibilidade em comparação ao uso de dietas artificiais (KIM et al., 1996). Essas enzimas digestivas dos alimentos vivos auxiliam na digestão na fase inicial das larvas (DABROWSKI \&
GLOGOWSKI, 1977), sendo à alta atividade proteolítica das enzimas planctônicas, responsáveis pela rápida degeneração e assimilação do plâncton pela larva (GALVÃO et al., 1997). Entretanto, somente a menor parte do total das enzimas ativas são oriundas de organismos ingeridos (UEBERSCHÄR, 1995), sendo a maior parte destas enzimas sintetizadas pela própria larva como uma reação ao estímulo físico pela ingestão da comida (YÚFERA \& DARIAS, 2005).

Deve-se ainda considerar que uma vantagem do alimento vivo sobre a ração é que este é mais facilmente detectado e capturado pelas larvas, por estimulá-las visualmente e quimicamente (TESSER \& PORTELLA, 2006), confirmando a necessidade do alimento vivo na alimentação inicial das larvas de tambaqui.

As larvas de tambaqui alimentadas com PR apresentaram melhor peso e comprimento aos demais tratamentos, o que foi observado para larvas de pacu Piaractus mesopotamicus (BEERLI et al., 2004) e surubim-do-iguaçu (FEIDEN et al., 2006) e mandi-pintado (DIEMER et al., 2010). Alimentar as larvas com alimentos vivos por um curto período de tempo antes da ração pode aumentar a atividade digestiva e aumentara capacidade das larvas de digerir dietas formuladas (CARNEIRO et al., 2003).

O acréscimo de ração ao alimento vivo (plâncton) tem proporcionado melhores desempenhos produtivos como observado para larvas de piracanjuba Brycon orbignyanus (PEDREIRA \& SIPAÚBATAVARES 2002), jundiá Rhamdia quelen (CARNEIRO et al., 2003), pirarucu Arapaima gigas (CAVERO et al., 2003) e peixe-rei Odonthesthes banariensis (PIEDRAS \& POUEY 2004). Esses melhores resultados são explicados pela decomposição do 
Rev. Bras. Saúde Prod. Anim., Salvador, v.16, n.2, p.440-448 abr./jun.., 2015 http://www.rbspa.ufba.br ISSN 15199940

plâncton facilitar a assimilação da ração nos primeiros dias de alimentação exógena, quando o trato digestivo está em formação (SERRANO JUNIOR, 2012). Ou seja, a capacidade das larvas em digerir ou não dieta seca, está relacionado com o estágio morfológico do trato digestivo e das enzimas secretadas ao longo do seu desenvolvimento (MARQUES et al., 2007; PORTELLA \& DABROWSKI, 2008).

Neste experimento, as larvas de tambaqui alimentadas com PR e PSR apresentaram maior peso $\mathrm{e}$ comprimento, como observado também para larvas de pacamã Lophiosilurus alexandri (PEDREIRA et al., 2008), com tratamentos semelhantes.

Neste estudo a oferta do plâncton selecionado em uma peneira com maior abertura foi favorável às larvas de tambaqui, que tiveram a sua disposição presas de maior porte para serem ingeridas, resultando em maior crescimento. Larvas de pacamã apresentaram maior crescimento em tratamentos alimentares com alimento vivo, e selecionado com peneira de maior diâmetro $(1300 \mu \mathrm{m})$, e maior número de copépodos (organismos de maior porte), proporcionando um maior crescimento (PEDREIRA et al., 2008).

A utilização de ração, como única fonte de alimento mostrou-se inadequada, sendo necessário o emprego do alimento vivo, que quando suplementado com a ração, proporcionou melhor desempenho produtivo e sobrevivência às larvas de tambaqui.

\section{AGRADECIMENTOS}

À Fundação de Amparo à Pesquisa de Minas Gerais, Banco do Nordeste do Brasil, Coordenação de Aperfeiçoamento de Pessoal de
Nivel Superior e ao Conselho Nacional de Desenvolvimento Científico e Tecnológico pelo apoio financeiro e a Companhia de Desenvolvimento dos Vales do São Francisco e Parnaíba pelas larvas.

\section{REFERÊNCIAS}

ARANA, L.V. Princípios químicos da qualidade de água em aquicultura: uma revisão para peixes e camarões. 2.ed. Florianópolis: Universidade Federal de Santa Catarina, 2004. 231p.

BARCELLOS, L.J.G.; KREUTZ, L.C.; QUEVEDO, R.M.; FIOREZE, I.; CERICATO, L.; SOSO, A.B.; FAGUNDES, M.; CONRAD, J.; BALDISSERA, R.K.; BRUSCHI, A.; RITTER, F. Nursery rearing of jundiá Rhamdia quelen (Quoy\&Gaimard) in cages: cage type, stocking density and stress response to confinement.

Aquaculture, v.232, p.383-394, 2004.

BARAS, E.; JOBLING, M. Dynamics of intracohort cannibalism in cultured fish. Aquaculture Research, v.33, p.461-479, 2002.

BRANDÃO-GONÇALVES, L.; SEBASTIEN, N.Y. Feeding activity and influence of intraspecific competition on zooplankton communities by jundiá (Rhamdia quelen Quoy and Gaimard, 1824) in laboratory. Brazilian Journal of Biology, v.73, p.765-773, 2013.

CARNEIRO, P.C.F.; MIKOS, J.D.; SCHORER, M.; OLIVEIRA FILHO, P.R.C.; BENDHAK, F. Live and formulated diet evaluation through initial growth and survival of jundiá larvae, Rhamdia quelen. Scientia Agrícola, v.60, p.615-619, 2003. 
Rev. Bras. Saúde Prod. Anim., Salvador, v.16, n.2, p.440-448 abr./jun.., 2015 http://www.rbspa.ufba.br ISSN 15199940

CAVERO, B.A.S.; PEREIRA-FILHO, M.; ROUBACH, R.; ITUASSÚ, D.R.; GANDRA, A.L.; CRESCÊNCIO, R. Efeito da densidade de estocagem na homogeneidade do crescimento de juvenis de pirarucu, em ambiente confinado. Pesquisa Agropecuária Brasileira, v.38, p.103-107, 2003.

DABROWSKI, K.; GLOGOWSKI, J. Studies on the role of proteolitic enzymes in digestion processes in fish. Hidrobiologia, v.54, p.129-134. 1997.

DAS, P.; MANDAL, S.C.; BHAGABATI, S.K.; AKHTAR, M.S.; SINGH, S.K. Important live food organism and their role in aquaculture. Frontiers in Aquaculture, v.5, p.6986, 2012.

DIEMER, O.; NEU, D.H.; SARY, C.; FEIDEN, A.; BOSCOLO, W.R.; SIGNOR, A.A. Manejo alimentar na larvicultura do mandi - pintado,( Pimelodus britskii). Revista Brasileira de Saúde na Produção Animal [online], v.11, n.3, p.903-908, 2010.

DIEMER, O.; NEU, D.H.; SARY, C.; FINKLER, J.K.; BOSCOLO, W.R.; FEIDEN, A. Artemia sp. Na alimentação de larvas de jundiá (Rhamdia quelen). Ciência Animal Brasileira, v.13, p.175-179, 2012.

DURAY, M.M.; ESTUDILLO, C.B.; ALPASAN, L.G. Larval rearing of the grouper Epinephelus suillu sunder laboratory conditions. Aquaculture, v.150, p.63-76, 1997.

FEIDEN, A.; HAYASHI, C.; BOSCOLO, W.R. Desenvolvimento de larvas de surubim-do-Iguaçú (Steindachneridion melanodermatum) submetidas a diferentes dietas. Revista Brasileira de Zootecnia, v.35, p.22032210, 2006.
FREGADOLLI, C.H. Food selection of pacu Piaractus mesopotamicus Holmberg, 1887 and tambaqui Colossoma macropomum Cuvier, 1818 larvae in the laboratory. Boletim Técnico do CEPTA, v.6, p.1-50, 1993.

GALVÃO, L.S.; VITORELLO, I.; FORMAGGIO, A.R. Relationships of spectral reflectance and color among near- and sub-surface horizons of tropical soil profiles. Remote Sensing of Environment, v.61, p.24-33, 1997.

GRAEB, B.D.S.; DETTMERS, J.M.; WAHL, D.H.; CÁCERES, C. Fish size and prey availability affect growth, survival, prey selection and foraging behavior of larval yellow perch.

Transactions of the American Fisheries Society, v.27, p.504-514, 2004.

KIM, S.G.; HU, X.; ADRIANY, G.; UGURBIL, K. Fast interleaved echoplanar imaging with navigator: High resolution anatomic and functional images at 4 Tesla. Magnetic

Resonance in Medicine, v.35, p.895902, 1996.

LOPES, J.M.; PASCOAL, L.A.F.; SILVA FILHO, F.P.; SANTOS, I.B.; WATANABE, P.H.; ARAÚJO, D.M.; PINTO, D.C.; OLIVEIRA, P.S. Farelo de babaçu em dietas para tambaqui.

Revista Brasileira de Saúde e Produção Animal [online], v11, n.2, p.519-526, 2010.

LUZ, R.K.; ZANIBONI-FILHO, E. Utilização de diferentes dietas na priemira aliemntação do mandi-amarelo (Pemielodus maculatus, Lacépéde). Acta Scientiarium, v.23, n.2, p.483489, 2001. 
Rev. Bras. Saúde Prod. Anim., Salvador, v.16, n.2, p.440-448 abr./jun.., 2015 http://www.rbspa.ufba.br ISSN 15199940

MANDAL, S.C.; DAS, P.; SINGH, S.K.; BHAGABATI, S.K. Feeding of aquarium fishes with natural and artificial foods: available options and future needs. Aqua International, v.3, p.20-23, 2009.

MARQUES, N.R.; HAYASHI, C.; GALDIOLI, E.M.; FERNANDES, E.B. Seletividade alimentar de organismos alimento por formas jovens de pacu Piaractus mesopotamicus (Holmberg, 1887) e curimba Prochilodus lineatus (Valenciennes, 1836). Acta Scientiarium Biological Science, v.29, p.167-176, 2007.

MENEZES, J.T.B.; QUEIROZ, L.J. de; DORIA, C.R.C.; MENEZES JUNIOR, J.B. Avaliação espermática pósdescongelamento em tambaqui, Colossoma macropomum (Cuvier, 1818). Acta Amzonica, v.38, p.365-368, 2008.

MUNIZ, J.A.S.M.; CATANHO, M.T.J.A.; SANTOS, A.J.G. Influência do fotoperíodo natural na reprodução induzida do tambaqui, Colossoma macropomum (CUVIER, 1818). Boletim do Instituto de Pesca, v.34, p.205-211, 2008.

PEDREIRA, M.M.; SIPAÚBATAVARES, L.H. Effect of prey selection and ration addition on the rearing of piracanjuba larvae, Brycon orbignyanus.

Boletim do Laboratório de Hidrobiologia, v.14-15, p.99-109, 2002.

PEDREIRA, M.M.; SANTOS, J.C.E.; SAMPAIO, E.V.; PEREIRA, N.P.; SILVA, J.L. Efeito do tamanho da presa e do acréscimo de ração na larvicultura de pacamã. Revista Brasileira de Zootecnia, v.37, p.1144-1150, 2008.

PEREIRA JUNIOR, G.P.; PEREIRA, E.M.O.; PEREIRA FILHO, M.; BARBOSA, P.S.; SHIMODA, E.; BRANDÃO, L.V. Desempenho produtivo de juvenis de tambaqui (Colossoma macropomum Cuvier, 1818) alimentados com rações contendo farinha de crueira de mandioca (Maniho tesculenta, Crantz) em substituição ao milho (Zeamays). Acta Amazonica, v.43, p.217-226, 2013.

PEREIRA J.G.; PEREIRA FILHO, M.; ROUBACH, R.; BARBOSA, P.S.; SHIMODA, E. Farinha de folha de leucena (Leucaena leucocephala Lam.) como fonte de proteína para juvenis de tambaqui (Colossoma macropomum CUVIER, 1818). Acta Amazonica, v.43, p.227-234, 2013.

PIEDRAS, S.R.N.; POUEY, J.L.O.F. Alimentação de alevinos de peixe-rei (Odontesthes bonariensis) com dietas naturais e artificiais. Ciência Rural, v.34, p.1203-1206, 2004.

PORTELLA, M.C.; DABROWSKI, K. Diets, physiology, biochemistry and digestive tract development of freshwater fish larvae. In: CYRINO, J.E.C.; BUREAU, D.; KAPOOR, B.G. (Orgs.). Feeding and digestive functions of fishes. Enfield: Science Publishers, 2008. p.227-279.

SANTOS, G.M. dos; SANTOS, A.C.M. dos. Sustentabilidade da pesca na Amazônia. Estudos Avançados, v.19, p.165-182, 2005.

SERRANO JUNIOR, A.E. Changes in gut evacuation time of larval mud crab, Scylla serrata (Crustacea: Portunidae) fed artificial plankton or live food. AACL Bioflux, v.5, p.240-248, 2012.

SILVA, C.A.; CARNEIRO, P.C.F. Qualidade da água na engorda de tambaquis em viveiros sem recirculação de água. Aracaju, SE: Embrapa Tabuleiros Costeiros, 2007, 2p. 
Rev. Bras. Saúde Prod. Anim., Salvador, v.16, n.2, p.440-448 abr./jun.., 2015 http://www.rbspa.ufba.br

SIPAÚBA-TAVARES, L.H.; BRAGA,

F.M.S. The feeding activity of

Colossoma macropomum larvae

(tambaqui) in fishponds with water

hyacinth (Eichhornia crassipes)

fertilizer. Brazilian Journal Biology, v.67, p.459-466, 2007.

TESSER, M.B.; PORTELLA, M.C.

Ingestão de ração e comportamento de larvas de pacu em resposta a estímulos químicos e visuais. Revista Brasileira de Zootecnia, v.35, p.1887-1892, 2006.

UEBERSCHÄR, B. The use of tryptic enzyme activity measurement as a nutritional condition index: laboratory calibration data and field application.

ICES Marine Science Symposium, v.201, p.119-129, 1995.

VEJA-ORELLANA, O;

FRACALOSSI, D; SUGAI, J;

FRACALOSSI, D.M. Dourado

(Salminusbrasiliensis) larviculture:

Weaning and ontogenetic development of digestive proteinases. Aquaculture, v.252, p.484-493, 2006.

WEINGARTNER, M.; ZANIBONIFILHO, E. Efeito de fatores abióticos na larvicultura de pintado-amarelo Pimelodus maculatus (Lacépède, 1803): salinidade e cor de tanque. Acta

Scientiarum, Animal Sciences, v.26, p.151-157, 2004.

YÚFERA, M.; DARIAS, M.J. The onset of exogenous feeding in marine fish larvae. Aquaculture, v.268, p.5363, 2005.

Data de recebimento: 04/11/2014

Data de aprovação: 11/05/2015 